\title{
Feasibility and clinical effectiveness of pre- hospital prothrombin complex concentrates (Octaplex/Beriplex) in anticoagulated patients with traumatic intracranial haemorrhage
}

\author{
Ben Brooks ${ }^{1 *}$, Suzanne Kellett ${ }^{2}$, Simon Hughes ${ }^{2}$ \\ From London Trauma Conference 2014 \\ London, UK. 9-12 December 2014
}

\section{Background}

Incidence and mortality from traumatic intra-cranial haemorrhage (ICH) is increased in patients on warfarin [1]. Prothrombin Complex Concentrates (PCC) rapidly reverse warfarin anti-coagulation and have been shown to reduce haematoma expansion and mortality in warfarinised patients sustaining ICH [2].

We aimed to determine the feasibility of pre-hospital use of PCCs by physicians and their clinical effectiveness in warfarinised patients sustaining traumatic $\mathrm{ICH}$.

\section{Method}

Patients were identified from the Trauma Audit and Research Network (TARN) database. We recorded demographic data, transfer method, injury mechanism and severity, time to blood sampling and reversal of anticoagulation, effectiveness of PCCs and patient outcome data.

\section{Results}

197 patients aged over 60 with traumatic ICH were admitted to University Hospital Southampton between April 2012 and May 2014. Mean age was 79 (range 61-98). More patients, 32/197 (16\%), were anti-coagulated with warfarin, than other study populations (9\%) [3]. One patient arrived by helicopter.

International Normalised Ratio (INR) was obtained within 8 hours of admission in $80 \%$ of cases. Failure to achieve this target was usually a result of inadequacy of samples sent. A small number of patients died before

\footnotetext{
* Correspondence: bmb3g11@soton.ac.uk

${ }^{1}$ Faculty of Medicine, University of Southampton, Southampton, UK

Full list of author information is available at the end of the article
}

samples could be obtained. 11\% (21/197) of patients had an INR $\geq 2.0$, and were reversed with PCC and vitamin K. Post-reversal INR $\leq 1.5$ was not achieved in two patients $(I N R=1.6)$. Overall mortality for warfarinised patients $(25 \%)$ was higher than their non-anti-coagulated counterparts (15\%).

\section{Discussion}

Only one anti-coagulated patient with traumatic ICH was treated by a pre-hospital physician. The majority of these patients received timely and effective reversal of their anticoagulation in-hospital following current guidelines. Notably, only $11 \%$ had an INR $>2$.

Pre-hospital PCC use requires investment in portable near-patient testing, interpretation of results and prescription of blood products. Our results support rapid transfer to hospital and timely, preferably near-patient, testing rather than investment in pre-hospital PCC use.

\section{Authors' details}

'Faculty of Medicine, University of Southampton, Southampton, UK. ${ }^{2}$ Shackleton Department of Anaesthetics, University Hospital Southampton Foundation Trust, Southampton, UK.

Published: 11 September 2015

\section{References}

1. Kalina M, Tinkoff $G$, Gbadebo A, Veneri P, Fulda G: A protocol for the rapid normalisation of INR in trauma patients with intracranial haemorrhage on prescribed warfarin therapy. American Surgeon 2008, 74:858-61.

2. Kuwashiro T, Yasaka M, Itabashi R, Nakagaki H, Miyashita F, Naritomi H, Minematsu K: Effect of prothrombin complex concentrate on haematoma enlargement and clinical outcome in patients with anticoagulant-associated intracerebral hemorrhage. Cerebrovascular Disease 2011, 31:170-6. 
3. Dossett L, Riesel J, Griffin M, Cotton B: Prevalence and Implications of Preinjury Warfarin Use: An Analysis of the National Trauma Databank. JAMA Surgery 2011, 146:565-570.

doi:10.1186/1757-7241-23-S2-A14

Cite this article as: Brooks et al:: Feasibility and clinical effectiveness of pre-hospital prothrombin complex concentrates (Octaplex/Beriplex) in anticoagulated patients with traumatic intracranial haemorrhage.

Scandinavian Journal of Trauma, Resuscitation and Emergency Medicine 2015 23(Suppl 2):A14.

Submit your next manuscript to BioMed Central and take full advantage of:

- Convenient online submission

- Thorough peer review

- No space constraints or color figure charges

- Immediate publication on acceptance

- Inclusion in PubMed, CAS, Scopus and Google Scholar

- Research which is freely available for redistribution

Submit your manuscript at www.biomedcentral.com/submit 